\title{
Controlling electric vehicle charging points for congestion management of UK LV networks
}

DOI:

10.1109/ISGT.2015.7131843

Link to publication record in Manchester Research Explorer

\section{Citation for published version (APA):}

Petrou, K., Quiros, J., \& Ochoa, L. F. (2015). Controlling electric vehicle charging points for congestion management of UK LV networks. In IEEE/PES Innovative Smart Grid Technologies ISGT 2015 (pp. 1-5) https://doi.org/10.1109/ISGT.2015.7131843

\section{Published in:}

IEEE/PES Innovative Smart Grid Technologies ISGT 2015

\section{Citing this paper}

Please note that where the full-text provided on Manchester Research Explorer is the Author Accepted Manuscript or Proof version this may differ from the final Published version. If citing, it is advised that you check and use the publisher's definitive version.

\section{General rights}

Copyright and moral rights for the publications made accessible in the Research Explorer are retained by the authors and/or other copyright owners and it is a condition of accessing publications that users recognise and abide by the legal requirements associated with these rights.

\section{Takedown policy}

If you believe that this document breaches copyright please refer to the University of Manchester's Takedown Procedures [http://man.ac.uk/04Y6Bo] or contact uml.scholarlycommunications@manchester.ac.uk providing relevant details, so we can investigate your claim.

\section{OPEN ACCESS}




\section{Controlling Electric Vehicle Charging Points for Congestion Management of UK LV Networks}

\author{
Kyriacos Petrou \\ The University of Manchester \\ Manchester, UK \\ krspetrou@gmail.com
}

\author{
Jairo Quiros-Tortos \\ The University of Manchester \\ Manchester, UK \\ jairoquirostortos@ieee.org
}

\author{
Luis F. Ochoa \\ The University of Manchester \\ Manchester, UK \\ luis_ochoa@ieee.org
}

\begin{abstract}
High penetration of Electric Vehicles (EVs) in residential UK Low Voltage (LV) networks may result in significant asset congestion (transformers and cables), particularly during peak hours. Therefore, this work proposes an implementable, centralized control algorithm that manages $\mathrm{EV}$ charging points to mitigate congestion in LV networks. To assess the need of control actions to avoid congestion issues, this work initially quantifies the potential impacts of different $\mathrm{EV}$ penetration levels on a real UK LV network. To demonstrate the effectiveness of the proposed control algorithm, analyses for uncontrolled and controlled charging of EVs are carried out. Monte Carlo simulations (considering 1-min resolution data) are undertaken to cater for domestic and EV load profile uncertainties. Results for this particular LV network indicate that asset congestion might occur for EV penetration levels larger than $40 \%$. More importantly, the results show the effectiveness of the proposed centralized control algorithm in avoiding the congestion effects on the LV network, even for a $100 \%$ penetration of EVs.
\end{abstract}

Index Terms--Congestion management, electric vehicles, low voltage networks, real-time control.

\section{INTRODUCTION}

The adoption of domestic electric vehicles (EVs) in the $\mathrm{UK}$ is expected to increase in the future given their potential contribution to reduce greenhouse gases and dependency on fossil fuels [1]. However, the uncontrolled charging of these EVs might lead to technical impacts on the very infrastructure they will be connected to: the residential low voltage (LV) networks. Indeed, part of the electricity demand from high penetrations of EVs is likely to be coincident with the peak demand of households, resulting in significant stress on the LV networks [2-5]. Although this depends on the penetration level of EVs and the characteristics of the corresponding LV network (topology, size, etc.), significant asset congestion (transformers and cables) might occur.

To cope with the potential impacts of EVs on distribution networks, different ways to manage EV charging demands have been investigated in recent years [3-7]. In general, these and similar studies propose the use of complex optimization approaches that require extensive information of the network (e.g., voltages and currents), the EVs (e.g., state of charge), and the electricity market (e.g., real-time pricing). These requirements make such approaches difficult to implement by Distribution Network Operators (DNOs) given that in practice real-time data is limited and many interoperability challenges still need to be addressed [8]. In addition, most of the few studies considering LV networks had been carried out adopting benchmark networks that may not reveal the particularities that can be found in real LV networks.

Therefore, an implementable, centralized control algorithm is proposed here to manage the EV charging points to avoid asset congestion, in particular the distribution transformer and the head of the feeders. This concept is based on the Esprit Technology - a patent recently filed by EA Technology Limited with PCT application number PCT/GB2012/050702 [9]. Unlike approaches found in the literature, the new control algorithm requires gathering only the status of the EV charging points and the currents at the substation. This makes this approach very practical, and thus, easier to adopt by DNOs. Moreover, a real residential LV network (six feeders and 351 customers) in the North West of England is studied here.

To assess the need of control actions to mitigate congestion issues, this work initially quantifies the impacts of different EV penetration levels on the real LV network. The impacts of uncontrolled and controlled charging of EVs are presented in terms of asset utilization, and the expected charging time. The analyses are carried out using Monte Carlo simulations in order to consider the uncertainties related to household demand as well as EV demand and location. The corresponding time-series demand profiles consider 1-minute resolution data for a typical weekday during winter time in the UK (worst case scenario, i.e., maximum demand). Three-phase power flow studies are adopted to cater for the voltage unbalance due to single-phase connections.

The paper is organized as follows. Section II describes the real LV network, as well as the creation of the domestic and EV load profiles. Section III then assesses the impacts of uncontrolled charging for different EV penetration levels. Section IV introduces the proposed control algorithm, and its effectiveness in managing the charging points to avoid asset congestion is demonstrated in Section V. Section VI discusses the main results, and Section VII finally presents the conclusions drawn from this study.

\section{INPUT DATA}

This section describes the input data used in this work: the residential LV network, the domestic and EV load profiles. 


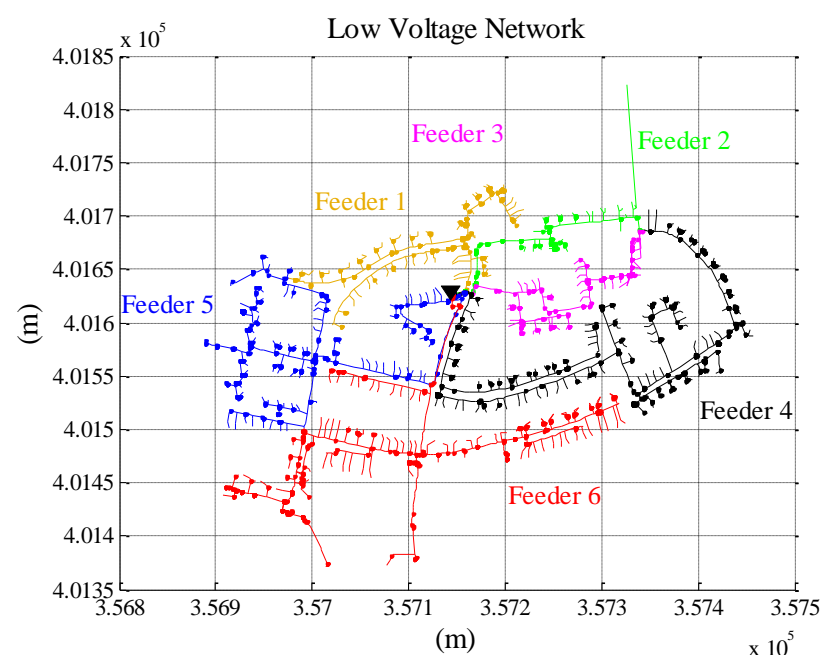

Figure 1. LV network topology.

TABLE I. LENGTH OF THE FEEDERS

\begin{tabular}{c|cccccc}
\hline Feeder & 1 & 2 & 3 & 4 & 5 & 6 \\
\hline No. Customers & 49 & 21 & 30 & 100 & 68 & 83 \\
\hline Length $(\mathrm{m})$ & 1222 & 670 & 780 & 2318 & 1830 & 1480 \\
\hline
\end{tabular}

\section{A. LV Network}

A real residential LV network from the North West of England is used here. The topology, power transformer, and type of conductor are fully modeled using OpenDSS [10]. This LV network is shown in Fig. 1. It consists of six feeders, a distribution transformer (black triangle), and 351 customers (modeled as domestic unrestricted). The busbar voltage of the transformer is considered to be $415 \mathrm{~V}$ (line-to-line) as per UK practice. Table I shows the length of the feeders and corresponding number of customers.

\section{B. Domestic Load Profiles}

The domestic load profiles used in this work correspond to a typical weekday during winter time (e.g., January), i.e., maximum demand in the UK. This period is selected to analyze the uncontrolled and controlled charging of EVs for the worst case scenario [11]. The time-series behavior of the domestic loads are created using the CREST tool [12]. This tool is used to generate a pool of profiles that are randomly allocated at customer nodes to model their demand at each Monte Carlo simulation. These profiles follow the percentage allocation of residents per household shown in Table II which are based on UK National Statistics [13].

TABLE II. DISTRIBUTION OF RESIDENTS PER HOUSEHOLD [13]

\begin{tabular}{c|ccccc}
\hline \# Residents & 1 & 2 & 3 & 4 & $5+$ \\
\hline Percentage (\%) & 30.6 & 34.1 & 15.6 & 12.9 & 6.8 \\
\hline
\end{tabular}

\section{EV Load Profiles}

The time-series behavior of the EVs are obtained using the stochastic data reported by an Irish trial [14] (start charging time and energy demanded during a connection). The probabilities of the start charging times are shifted three hours earlier to create a higher coincidence with the peak demand in the UK ( 7pm) [11]. This will further stress the LV network during peak hours; and hence, the benefits of the controller will be more evident. The EV battery charging process is assumed to be continuous, i.e., once it starts, it will stop until the bat- tery stops withdrawing power (e.g., user disconnects the vehicle or battery is fully charged). Additionally, it is assumed that EVs are connected only once per day, and their actual state of charge is unknown. The EVs considered in this work are similar to the commercially available Nissan Leaf, i.e., the battery capacity is $24 \mathrm{kWh}$. Only the slow charging mode is considered, i.e., a constant charging rate of $3 \mathrm{~kW}$ is used. The EVs load profiles are randomly allocated at customer nodes (according to the penetration level) in the Monte Carlo simulations. It is assumed that there is a maximum of one EV per household despite the number of residents.

\section{EV IMPACTS ON THE LV NETWORK}

This section quantifies the technical impacts of the uncontrolled charging of EVs on the residential LV network depicted in Fig. 1. The EV penetration levels are increased from $0 \%$ (base case) until 100\% in steps of $10 \%$. The analysis for each penetration level is based on a Monte Carlo approach with 15 simulations [15]. For each one, a time-series three-phase power flow is solved using OpenDSS [10].

It is worth mentioning that LV networks in the UK are operated with a voltage range of $+10 \% /-6 \%$ of nominal $(400 \mathrm{~V})$ [16]. In addition, the capacity of the transformer and cables in this LV network is $500 \mathrm{kVA}$ and $310 \mathrm{~A}$, respectively.

Fig. 2 shows a distribution of the transformer load for each penetration level where the red lines are the averages of the corresponding simulations. For this particular network, it can be noticed that transformer congestion might occur for penetration levels larger than $40 \%$. Therefore, for simplicity, only $60 \%$ and $100 \%$ are examined in detail below.

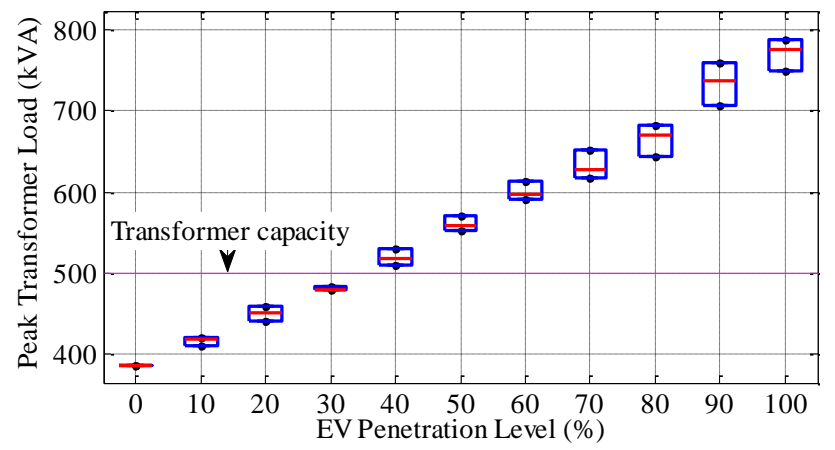

Figure 2. Peak transformer load for different EV penetration levels.

Fig. 3 shows the maximum (Max), average (Avg) and minimum (Min) transformer load curves during a typical weekday in January for a $60 \%$ penetration. It can be seen that transformer congestions occur from $6 \mathrm{pm}$ until $10 \mathrm{pm}$, with a maximum peak of $600 \mathrm{kVA}$ at $8 \mathrm{pm}$. Although this can be considered within a $20 \%$ cyclic rating of the transformer, it significantly affects the ageing of the asset [17]. However, if the penetration level increases to $100 \%$, transformer congestions might occur from $4 \mathrm{pm}$ until $11 \mathrm{pm}$ (see Fig. 4), dangerously exceeding its rating capacity at $8 \mathrm{pm}$ by $60 \%(800 \mathrm{kVA})$.

Fig. 5 (100\% penetration) shows the current at the head of Feeder 4 (the feeder with the most customers). As it can be noticed, Feeder 4 presents congestion problems (also found in Feeders 5 and 6). Finally, it is important to mention that for all the Monte Carlos simulations undertaken in this studied, this particular LV network does not present significant voltages problems for any penetration level. 


\section{Accepted Paper}

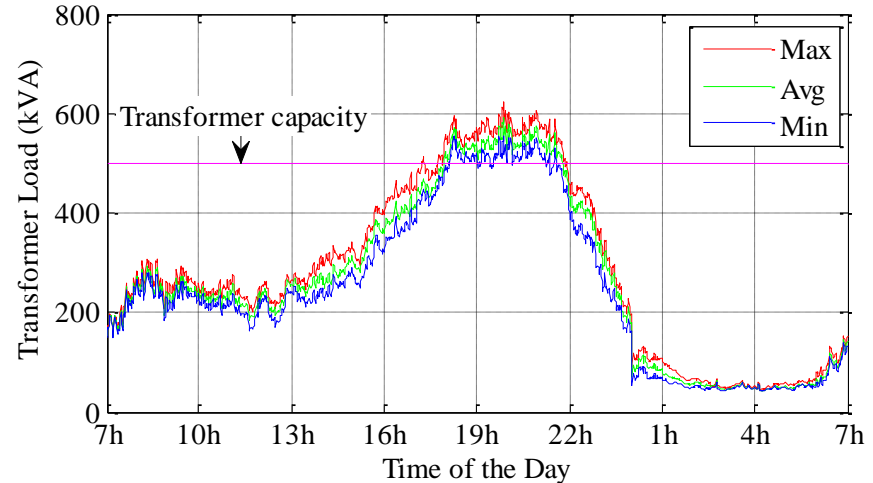

Figure 3. Transformer load for a $60 \%$ penetration.

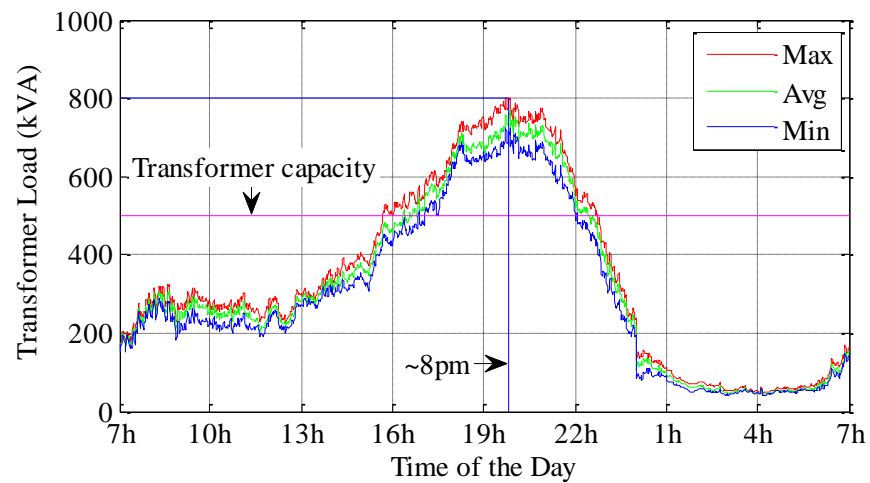

Figure 4. Transformer load for a $100 \%$ penetration.

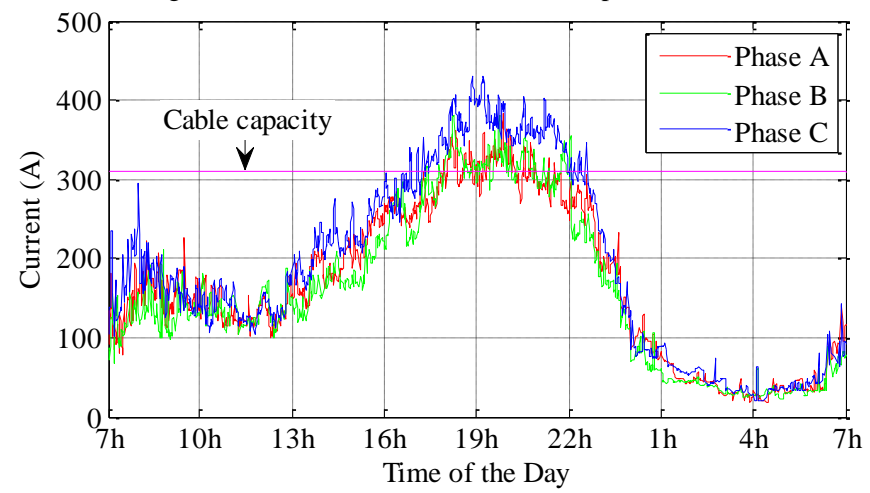

Figure 5. Current at the head of Feeder 4 for a $100 \%$ penetration.

The impact assessment carried out above highlights the need to undertake control actions to avoid technical problems presented in this and similar residential LV networks with high EV penetrations. In addition, for this particular network, it is clear that thermal issues are the most concerning ones.

\section{PROPOSED CONTROL ALGORITHM}

This section introduces the proposed centralized control algorithm to overcome the congestion problems found in the real LV network previously described. The conceptual approach is based on the Esprit Technology which has been presented in a patent recently filed by EA Technology Limited with PCT application number PCT/GB2012/050702 [9]. The control philosophy for this work has been developed internally and similarities with Esprit are unintentional.

\section{A. Control Algorithm}

The logic of the control algorithm, which is based on a $\mathrm{P}$ controller whose gain is set to be 0.5 to avoid excessive power changes in the network, is described below. At every control cycle of $1 \mathrm{~min}$, the power transfer at the transformer $\left(\mathrm{S}_{\mathrm{T}}\right)$, currents at the head of the feeders $\left(\mathrm{I}_{\mathrm{L}}\right)$, and the status of each $\mathrm{EV}$ charging point are collected and processed by the centralized control algorithm which in turns commands the new status of the charging points.

In practice, sensors and actuators at the charging points, sensors at the substation, communication infrastructure (e.g., mobile network), and a PLC-like device (at the substation) to host the control algorithm would only be needed to implement the proposed approach. No direct information (e.g., the state of charge) from the EVs is required.

\section{1) State of EV Charging Points}

The state of each EV charging point at each control cycle is labeled in the control algorithm as shown in Table III. The control algorithm contains a counter of the charge received by each EV during the operation. The charge received by each $\mathrm{EV}$ is used to identify the EVs to be disconnected and connected, as further detailed below. The counter is reset at 7:00am, as it is assumed that most of the users will start using their EV at this time [18].

TABLE III. LABELS GIVEN TO EV CHARGING POINTS

\begin{tabular}{c|l}
\hline Label & \multicolumn{1}{c}{ State } \\
\hline 0 & EV is not connected \\
1 & EV is connected and receiving charge \\
2 & EV is connected, but it is not receiving charge, as the controller \\
3 & temporally disabled its charging \\
\hline
\end{tabular}

\section{2) Congestion Assessment}

A critical feature of the control algorithm is to identify when the transformer and/or the head of the feeders are congested. EVs labeled 1 (see Table III) are disconnected only when these asset congestions are detected.

\section{a) Disconnection of $E V s$}

When asset congestions are identified in the LV network, the control algorithm disconnects EVs, i.e., it controls the charging points, following a hierarchical approach.

It initially checks the phases at the head of the feeders (for this network, 18 in total) for cable congestions. If the current in a phase exceeds its capacity (310 A), a number " $X$ " of EVs, defined by the P-controller, is disconnected from that phase. The identification of the most suitable EVs to be disconnected is detailed later in Section IV-A-3.

If transformer congestion is detected in the same control cycle, the number " $Y$ " of EVs that needs to be disconnected in the entire LV network is defined to reduce the transformer load. If enough EVs are to be disconnected due to cable congestions, i.e., if $\sum_{i=1, \ldots, 18} X_{i}>Y$, none extra EV is disconnected. However, if $\sum_{i=1, \ldots, 18} X_{i}<Y$, the additional number $\left(Y-\sum_{i=1, \ldots, 18} X_{i}\right)$ of EVs from the entire LV network is disconnected. As above, the identification of the most suitable EVs to be disconnected is detailed in Section IV-A-3.

\section{b) Connection of EV Charging Points}

The control algorithm connects EVs when possible. If the transformer load is below a deadband of 3\% of its rating capacity, the control algorithm checks for EVs with label 2 (see 


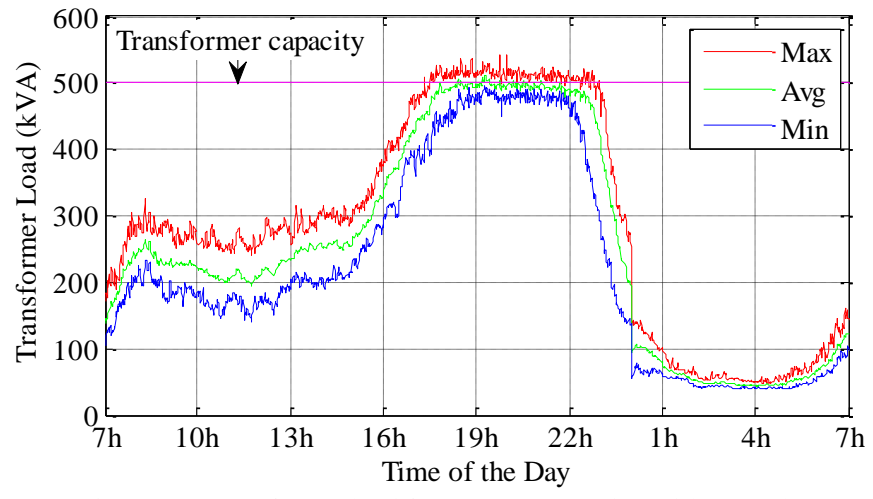

Figure 6. Transformer load for a $60 \%$ penetration with control.

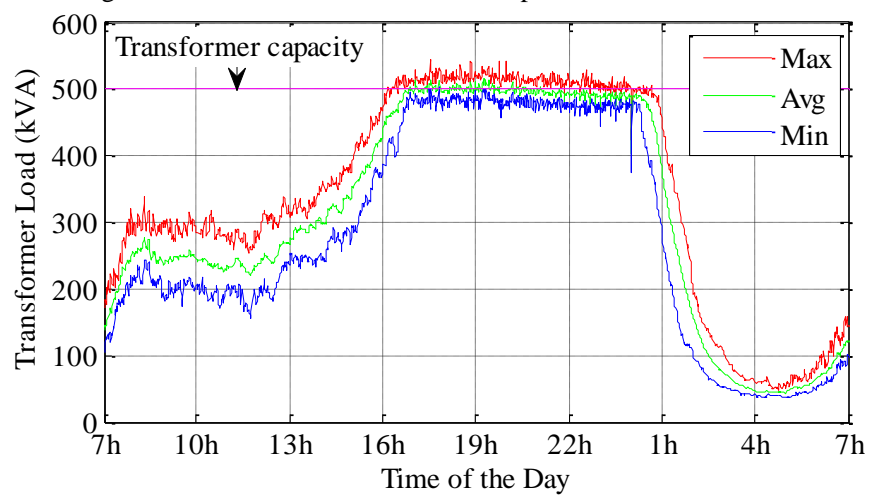

Figure 7. Transformer load for a $100 \%$ penetration with control.

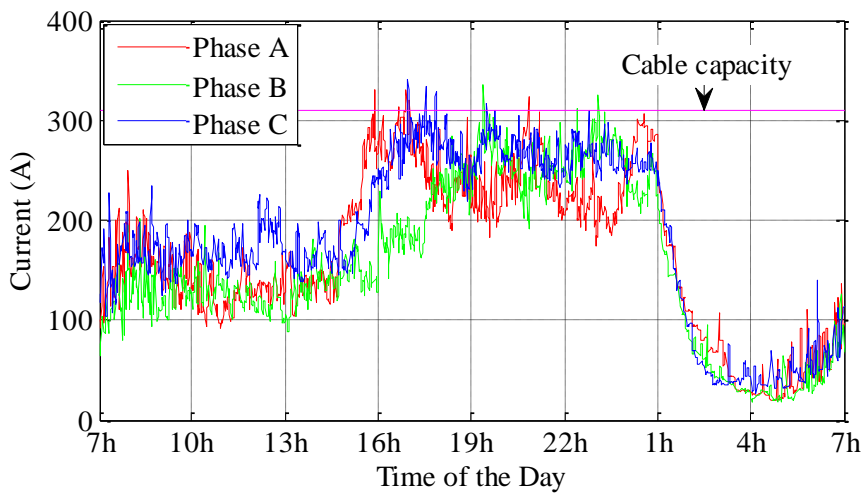

Figure 8. Current at the head of Feeder 4 for a $100 \%$ penetration with control.

Table III). It then reconnects a number ' $Z$ ' of EVs to continue their charging process. The identification of the EVs to be reconnected is detailed in Section IV-A-3. To prevent potential cable congestions, the control algorithm avoids reconnecting EVs on phases that are over $90 \%$ of their capacity.

\section{3) Disconnection and Connection Strategy}

Disconnection: When cable congestions are detected, all the EVs labeled 1 and connected at the congested phase are identified. The " $X$ " EVs that have received the most charge (whose counter is large) are disconnected to reduce congestions. The same procedure is followed at the transformer level to prevent transformer congestions. The control algorithm checks the charge received by all the EVs in the LV network, and disconnects those with the most charge received.

Connection: When the transformer load is below its capacity by $3 \%$, the control algorithm checks for EVs that are labeled 2. It then calculates using the P-Controller the number
" $Z$ " of EVs that can be reconnected. The " $Z$ " EVs that have received the least charge of all the EVs that are currently labeled 2 are reconnected first in each control cycle. However, if the current in a cable is above $90 \%$ of its capacity, no EV is reconnected on that phase to avoid possible cable congestions.

\section{APPliCATION OF THE CONTROL Algorithm}

This section presents the application of the control algorithm described in Section IV. Similar to the impact assessment, a Monte Carlo approach with 15 simulations is carried out. At each simulation, domestic and EV load profiles are randomly allocated at customer nodes. For consistency, penetration levels of $60 \%$ and $100 \%$ are examined to demonstrate the performance of the control algorithm.

Fig. 6 and 7 show the transformer load for a $60 \%$ and $100 \%$ penetration when the control algorithm is used, respectively. As noticed, the load demand is flattened by the control algorithm and the transformer congestions previously shown in Fig. 3 and 4 are no longer present. As expected, the transformer load remains close to $500 \mathrm{kVA}$ for a longer period for a $100 \%$ penetration level than for $60 \%$.

Fig. 8 shows the current at the head of Feeder 4. As it can be noticed, the cables are no longer congested. Congestion problems are also solved in all the other feeders of this particular network, even for a penetration level of $100 \%$.

\section{A. Effects on the original charging process}

In the uncontrolled charging, EVs are charged as required, i.e., they are not disconnected. Hence, the ratio between the actual time taken to charge an EV and the time required and expected by the user to charge the EV is always one. However, in the controlled charging, this may not always be the case, as some EVs are disconnected to avoid congestions, and they are later reconnected when problems are not presented.

For an EV penetration level of $60 \%$, Fig. 9 shows the probability distribution of the ratio between the actual time taken (controlled charging) and the originally required charge time (uncontrolled charging). It can be seen that EVs are charged within the original time $55 \%$ of the cases. Fig. 9 also shows that only $6 \%$ of the cases EVs will require twice the time that the user would have otherwise needed (uncontrolled charging). Due to the nature of the control algorithm, which disconnects EVs that have received the most charge, EVs that require the lesser charge are usually charged at near the expected time. For instance, an EV that requires 1 hour of charge is likely to be charged in 1 hour, but one EV that requires 5 hours might be charged in 10 hours. Finally, EVs that are connected when no congestion problems occur will be charged as originally required.

The original charging times are increased as the penetration level increases, i.e., the more EVs, the longer it may take to charge all of them as the users expected. Fig. 9 also shows that for a $100 \%$ of penetration, only in $33 \%$ of the cases EVs will be charged within the originally required charge time, $9 \%$ of the cases will require twice the time, and $4 \%$ triple the time. This is an unavoidable consequence of managing congestion with very high EV penetrations. 


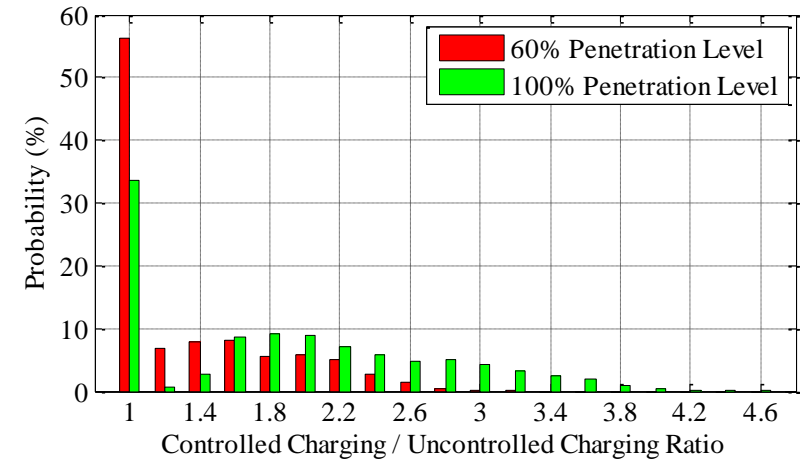

Figure 9. Histogram of actual time required to charge the EVs during weekdays in winter for a $60 \%$ and $100 \%$ penetration with control.

\section{DISCUSSION}

The proposed control algorithm is capable of preventing congestions in the LV network shown in Fig. 1. However, further improvements might be needed when implementing this control strategy in other LV residential networks, as voltage drops may become an important issue. Indeed, a much higher number of Monte Carlo simulations (e.g., 100) may highlight the necessity to adapt the control algorithm to cope with voltage problems at the customer nodes.

As depicted in Fig. 9 and 10, the control algorithm may cause some EVs to take twice the time to charge compared to the uncontrolled case. This may considerably delay the charging of EVs that required long charging times. Further research is needed to improve these charging times whilst limiting the amount of information required.

This paper has presented simulation results for a typical weekday during winter time in the UK. Simulation results for the entire year are extensively analyzed in [19].

\section{CONCLUSIONS}

This paper proposes an implementable, centralized control algorithm that manages EV charging points to avoid congestion in a real UK LV network. The impacts of uncontrolled and controlled charging of EVs are carried out using Monte Carlo simulations in order to consider the uncertainties related to household demand as well as EV demand and location. Time-series simulations are adopted considering 1-minute resolution data for a typical weekday during winter time in the UK (worst case scenario, i.e., maximum demand).

In the uncontrolled charging, asset congestion (transformer and cables) as well as voltage drops in highly loaded feeders, are likely to occur, in this particular LV network, for EV penetration levels larger than $40 \%$. Transformer congestions can take place for periods longer than 4 hours when the penetration level is larger than $60 \%$. Peaks overreaching the transformer capacity by $60 \%$ can occur for a penetration of $100 \%$.

The control algorithm that is proposed in this work can successfully prevent asset congestions by disconnecting EVs when the transformer and cables exceed their capacity. However, it results in longer charging times of EVs. This is an unavoidable consequence of managing congestion with very high EV penetrations. The larger the penetration level, the longer it takes for the control algorithm to charge the EVs.
Indeed, for a penetration level of $60 \%$, only $55 \%$ of the cases EVs will be charged within the originally required charge time (uncontrolled), and only a $6 \%$ may present delays of twice the original time. Finally, for a $100 \%$ penetration, the control algorithm operates from 5pm until 1am (next day), and $99 \%$ of the disconnections performed by the control algorithm are due to transformer congestions, which indicates that measurements at the transformer level are vital for the adequate operation of the proposed control algorithm.

\section{ACKNOWLEDGEMENT}

The authors would like to thank Electricity North West Limited (ENWL), UK, for providing the LV network data.

\section{REFERENCES}

[1] Committee on Climate Change, "Reducing the UK's carbon footprint and managing competitiveness risks," Apr. 2013.

[2] P. Zhang, K. Qian, C. Zhou, B. G. Stewart, and D. M. Hepburn, "A Methodology for Optimization of Power Systems Demand Due to Electric Vehicle Charging Load," IEEE Trans. Pow. Syst., vol. 27, pp. 1628-1636, Aug. 2012.

[3] K. W. Chan and X. Luo, "Real-time scheduling of electric vehicles charging in low-voltage residential distribution systems to minimise power losses and improve voltage profile," IET GTD, vol. 8, pp. 516529, Mar. 2014.

[4] K. J. Dyke, N. Schofield, M. Barnes, and S. Member, "The Impact of Transport Electrification on Electrical Networks," IEEE Trans. Industrial Electronics, vol. 57, pp. 3917-3926, 2010.

[5] R.-C. Leou, C.-L. Su, and C.-N. Lu, "Stochastic Analyses of Electric Vehicle Charging Impacts on Distribution Network," IEEE Trans. Pow. Syst., vol. in press, pp. 1-9, 2013.

[6] Z. Darabi and M. Ferdowsi, "Aggregated Impact of Plug-in Hybrid Electric Vehicles on Electricity Demand Profile," IEEE Trans. Sust. Energy, vol. 2, pp. 501-508, Oct. 2011.

[7] J. Hu, S. You, M. Lind, and J. Østergaard, "Coordinated Charging of Electric Vehicles for Congestion Prevention in the Distribution Grid," IEEE Trans. Smart Grid, vol. 5, pp. 703-711, Mar. 2014.

[8] Frontier Economics, "How to deliver smarter grids in GB," April 2011.

[9] John Sean Sinclair, "Power Demand Management on a Low Voltage Network with a Plurality of Intelligent Sockets," GB Patent PCT/GB2012/050702, 2014.

[10] Electric Power Research Institute - EPRI. Open Distribution System Simulator, 2012.

[11] Department of Energy \& Climate Change, "Energy Trends," Mar. 2014.

[12] I. Richardson and M. Thomson, "Intagrated simulation of Photovoltaic Micro-Generation and Domestic Electricity Demand: A one minute resolution open source model," in CREST - Department of Electronic and Electrical Engineering, Loughborough University, UK. 2010.

[13] Office of National Statistics, "2011 Census, Population Estimates by five-year age bands, and Household Estimates for Local Authorities in the United Kingdom," 2013.

[14] P. Richardson, M. Moran, A. Maitra, J. Taylor, and A. Keane, "Impact of electric vehicle charging on residential distribution networks: An Irish demonstration initiative," Stockholm.

[15] A. Navarro, L. F. Ochoa, and D. Randles, "Monte Carlo-based assessment of PV Impacts on real UK low voltage networks," in IEEE/PES General Meeting 2013, 2013, p. 5.

[16] Department of Trade and Industry, "The Electricity Safety, Quality and Continuity Regulations 2002," Oct. 2002.

[17] Y. Gao, N. Azis, Z. Wang, and D. Jones, "Impact of Electric Vehicles on the Thermal Performance of $11 \mathrm{kV}$ Distribution Transformers," in Euro TechCon, Glasgow, United Kingdom, 2012.

[18] Office of National Statistics, "National Travel Survey: 2010," Department of Transport, Ed., ed, 2013.

[19] K. Petrou, "Intelligent Control of Electric Vehicle Charging in Low Voltage Networks," The University of ManchesterMay 2014. 